\title{
Endoscopic evacuation of sacral hydatid cysts: case report
}

\author{
Bektas Açikgöz ${ }^{1}$, Cem Sungur ${ }^{1}$, Tunçalp Özgen ${ }^{2}$, Mehmet Çamurdanoğlu ${ }^{1}$ and Mustafa Berker ${ }^{1}$ \\ ${ }^{1}$ Bayindir Medical Centre, Bayindir Tip Merkezi, 06520 Sogutozu, Ankara, Turkey; ${ }^{2}$ Department of Neurosurgery \\ Hacettepe University Medical School. Ankara, Turkey
}

A case of hydatid disease of the intra and parasacral area is reported. This rare localization was probably due to previous abdominal hydatid cyst surgery. The patient underwent surgery, with a small opening in the SI lamina and the cysts were removed totally with the aid of a rigid endoscope. The surgical technique used and MRI findings are discussed.

Keywords: endoscopic surgery; sacral hydatid cysts; echinococcal infection

\section{Introduction}

Echinococcus granulosus infections are mainly encountered in the major sheep-raising and pastoral areas of the world. ${ }^{1-3}$ Typical cystic echinococcosis consists of a single, unilocular cyst; however 20 to $30 \%$ of cases may have multiple cysts in the same or multiple organs. Clinical manifestations and the prodromal period depend on the organ involved; central nervous system and eye lesions causing early symptoms. ${ }^{2,4}$ Symptoms associated with pulmonary and hepatic cysts are often related to pressure necrosis; obstruction of blood, lymphatic or bile flow; or rupture into bronchial, pleural, peritoneal or intrabiliary spaces. Cases involving other rare sites including the spine ${ }^{5}$ account for only 1 to $5 \%$ of total patients and are usually seen in highly endemic regions such as Turkey. ${ }^{2,6}$

We describe a patient with sacral hydatid cysts presenting with left leg pain due to root compression by the intraspinal extension of the cysts. This patient is presented because of the rare location and multiplicity of the hydatid cysts and the endoscopic surgical technique used in the treatment.

\section{Case report}

An 18-year-old woman was referred with low back pain radiating to the left leg starting 9 months previously and gradually worsened, sometimes awakening her at night. There was occasional pain in the perineal region. She had been constipated during the last 2 months but denied rectal or vaginal bleeding or urinary incontinence. There was no history of weight loss, night sweats or nausea. Past history revelaed recurrent hydatid cysts due to echinococcus granulosus. The patient was operated on in 1982 for multiple intraabdominal cysts when more than 20 cysts were removed and a splenectomy was also carried out. She underwent further surgery in 1984 and in 1986 for

Correspondence: Doçent Dr. Bektas Açikgöz recurrent hydatid cysts in the abdominal cavity and in 1986 was prescibed $400 \mathrm{mg} /$ day of Albendazole and received this drug for 6 months. In the last check-up in 1990 at another medical centre she was informed that there was a single hydatid cyst in the liver and was offered regular follow-up.

Physical examination was unremarkable except for a positive straight leg raising test of the left lower extremity.

Laboratory examination: $\mathrm{Hb}: 11.7 \mathrm{~g} / \mathrm{dL}, \mathrm{WBC}$ : $12.900 /$ cumm with a differential count of $49 \%$ Neutrophils, 43\% Lymphocytes, 4\% Monocytes and $2 \%$ band forms. Erythrocyte sedimentation rate $16 \mathrm{~mm} / \mathrm{h}$. Echinococcus specific IgE was positive.

Ultrasonographic examination and a CT-scan of the abdomen revealed a hydatid cyst $35 \mathrm{~mm}$ in diameter in the right kidney and confirmed the presence of another

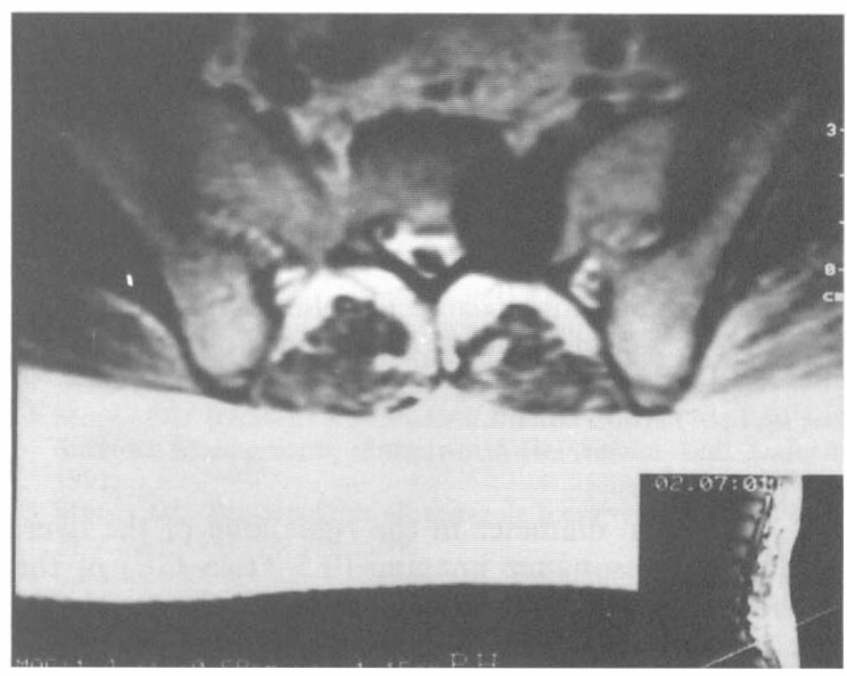

Figure 1 Axial section of T1-weighted image. A hypointense lesion indicating a hydatid cyst is seen. S1 root on the left side is not visible. The cyst has eroded the left S1 lamina 


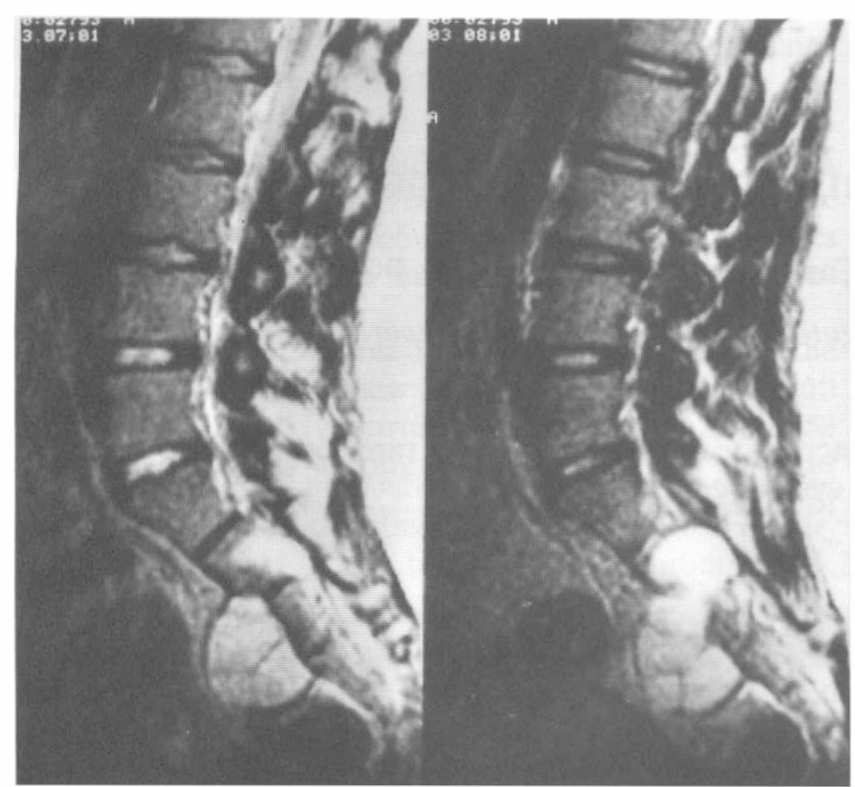

Figure 2 Sagittal section, T2-weighted images indicating hyperintense multilocular hydatid cysts intra and parasacrally

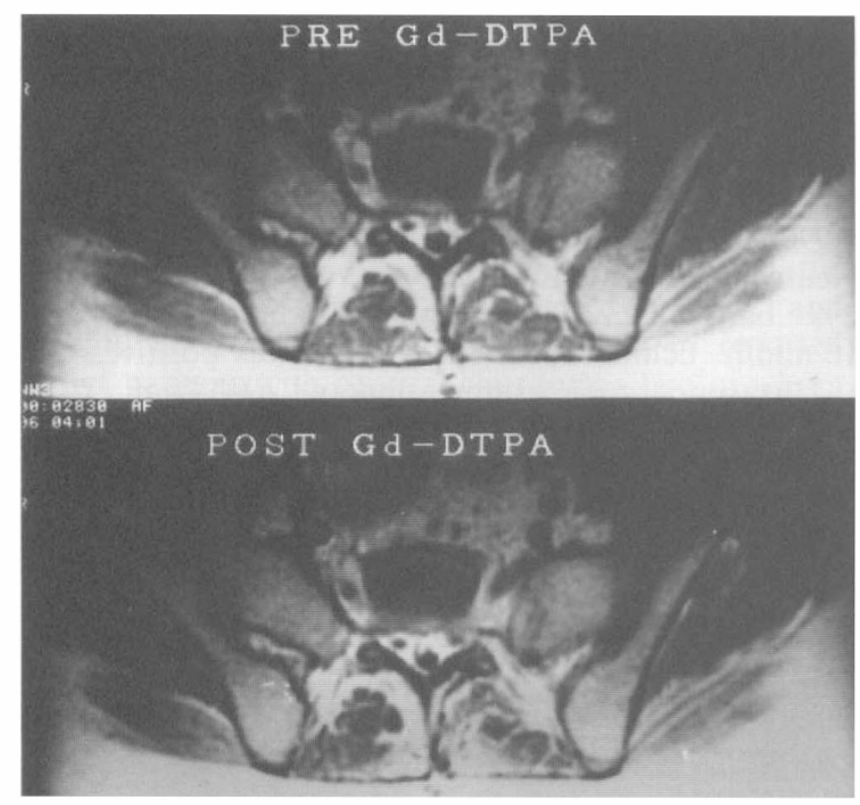

Figure 3 Postoperative axial section. Both $\mathrm{S} 1$ roots are now visible on T1-weighted images. No pathological enhancement after Gd-DTPA injection

cyst, $25 \mathrm{~mm}$ in diameter in the right lobe of the liver.

Magnetic resonance imaging ( 0.5 Tesla GE) of the lumbosacral spinal canal was done which revealed a cyst compressing the left S1 root (Figure 1). There were several other cysts extending from the interior of the sacrum to the parasacral area (Figure 2). These had the appearance of an alveolar-type hydatid cyst. In T1-weighted images the cyst compressing the S1

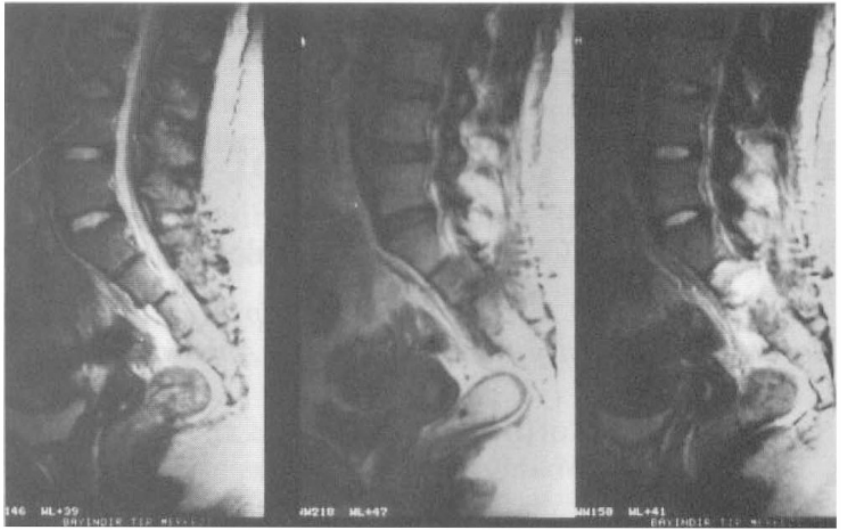

Figure 4 Postoperative sagittal sections indicating total removal of all the cysts. In the parasacral area only postoperative soft tissue changes are observed

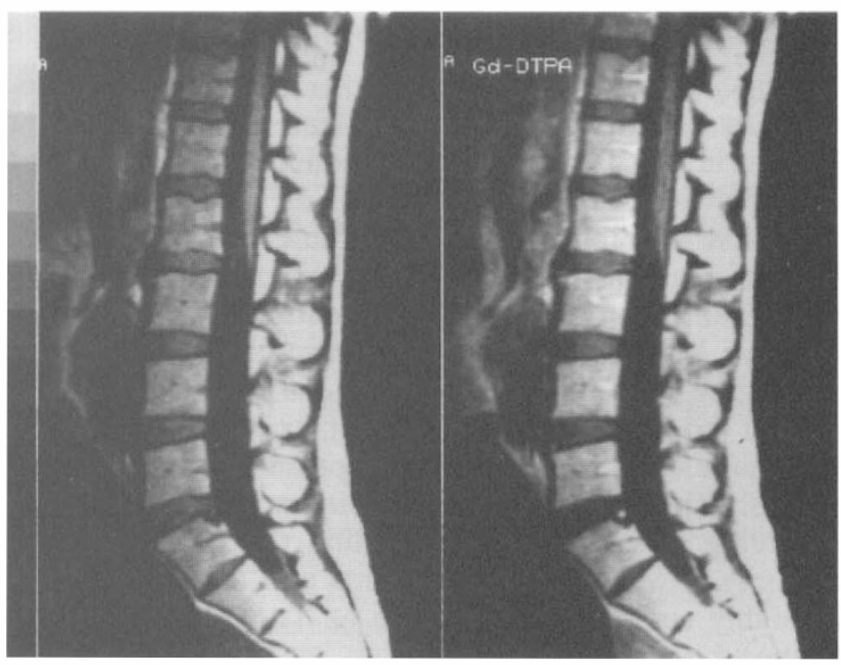

Figure 5 An intradural extramedullary hydatid cyst located between T12 and S2 segments. The right figure indicates T1 image after Gd-DTPA injection. There is no contrast enhancement

root was seen as a hypointense lesion, whereas fast spin $\mathrm{T} 2$-weighted images revealed a hyperintense lesion. The cysts had thin walls. Proton density studies did not yield further information.

Operation was carried out; a lower lumbosacral midline incision was made exposing the sacral laminae. The left S1 lamina was eroded by a hydatid cyst. This bony erosion was enlarged to enable the cyst to be removed. When the interior of the sacrum was explored with a rigid endoscope (Storz, 27018 B), several hydatid cysts were seen and were removed by irrigation with $3 \% \mathrm{NaCl}$. As some of the cysts had been opened during surgical intervention, the surgical site was irrigated carefully.

Histopathological examination of the cysts revealed cuticular and germinative membranes. Post-operative MRI studies (Figures 3 and 4) showed that there was 
complete removal of both the intrasacral and the parasacral hydatid cysts. The postoperative course was uneventful and the neurological situation was satisfactory.

Preoperatively the patient was prescribed Albendazole $40 \mathrm{mg} / \mathrm{kg} /$ day because of its efficacy against hydatid cysts localized to bone and the higher rate of complete cure obtained with this antihelmintic drug.

\section{Discussion}

Hydatid cyst of the spine occurs mainly in the thoracic spine either by direct extention from pulmonary infestation or primarily within the vertebral body.,7-9 Sacral spinal involvement is much more rare. ${ }^{7-9}$ According to Braithwaite and Lees ${ }^{10}$ the lesion may occur in five locations: (1) Primary intramedullary; (2) Intradural extramedullary; (3) Extradural intraspinal; (4) Within the vertebra and (5) Paravertebral. In our patient parasacral involvement probably occurred by direct spread from the previous abdominal surgery, and according to the above classification our case can be classified as types 3 and 5 .

In the literature the role of MRI in the diagnosis of hydatid cysts is well described. ${ }^{1,9,11,12}$ The cysts appear mainly as low-signal intensity on T1 images, and show high-intensity characteristics in T2 studies. $9,11,12$ Marani et $a l^{12}$ also reported medium intensity for proton density-weighted images. Correlation between histopathological and MRI findings were also found. ${ }^{9,11}$ Jena et $a l^{11}$ in their case report advised T2 images for detecting the viability of the cysts. On the other hand, Tekkök and Benli ${ }^{9}$ after evaluating MRI and histopathological findings stated that proton density studies were more useful in the delineation of cyst viability. In our case the alveolar appearance of the cysts inside the sacrum and parasacral area differed from Tekkök's patient which was described as a 'bunch of grapes'. The alveolar shape of our lesion favoured endoscopic surgery and removal of the cysts through a small opening. For further investigation, Gadolonium-DTPA enhancement of the cyst hydatid can be used, unfortunately a contrast study was not done in the presented case, but our previous experience proved that hydatid cysts do not enhance after Gd-DTPA (1 mmol/kg) injection (Figure 5).

The pioneer of neuroendoscopic surgery was L'Espinasse who performed the first ventriculoscopy in $1904^{13}$ when he cauterized the choroid plexus of two infants with hydrocephalus. Today technological improvements in endoscopes makes it possible to perform complex neuroendoscopic procedures without major tissue traumatization. ${ }^{4,15}$

Bauer and Hellwig ${ }^{14}$ called this endoscopic surgery 'Minimally Invasive Endoscopic Neurosurgery (MIEN)'. MIEN refers to neurosurgical operations in which larger openings of intracranial and intraspinal spaces can be avoided.

In the present case the endoscope provided direct vision inside the sacrum enabling location of several hidden hydatid cysts. It also enabled us to remove all of the cysts under direct vision. Besides good illumination within the sacrum, endoscopic surgery also avoided the need for extensive laminectomy and through a small incision all of the cysts could be removed. This approach allowed us to remove the cysts which were in close relation with each other one by one.

It can be argued that the disadvantage of such surgery was perforation of the cyst wall. But surgeons removing hydatid cysts of the spine know that the cysts do perforate during removal because of adherance to surrounding tissues especially bone tissue. $^{7,8}$ For this reason the surgical site must be irrigated carefully with hypertonic $\mathrm{NaCl} .^{8,16}$

Endoscopic spinal surgery is prescribed for hydromyelia, syringomyelia and discectomy. ${ }^{14,15}$ It has also been proposed as an alternative method for the treatment of intracranial cystic lesions and of brain abscess. ${ }^{15}$ A review of the literature failed to find a similar report of endoscopic removal of spinal hydatid cysts.

As the recurrence rate is high for epidural hydatid cysts $^{4,5,8}$ it is advised that the patients should be medicated with albendazole for at least a year. Our patient received albendazole in the postoperative period for a year and follow-up examinations up to a year after the operation revealed that there was no recurrent disease.

\section{Conclusion}

We have described a rare case of intrasacral and parasacral hydatid disease in which we employed a different surgical technique. MRI findings of this case are also discussed in the light of previous literature. Endoscopic surgery in this patient not only helped to identify and treat all of the cysts but also avoided an extensive laminectomy.

\section{References}

1 Bavbek M, Inci S, Tahta K, Bertan V. Primary multiple spinal extradural hydatid cysts: Case report and review of the literature. Paraplegia 1992; 30: 517 - 519.

2 Kalyoncu AS. Selçuk ZT, Emri S. Echinococcosis in the Middle East and Turkey. Rev Infect Dis 1991 13: 1029-1030.

3 Williams JF, Lopez AH, Trejos A. Current pervalence and distribution of hydatidosis with special reference to Americas. Am J Trop Med Hyg 1971; 20: $224-236$.

4 Morris DL, Richards KS: Hydatid Disease Current Medical and Surgical Management. Butterworth-Heinemann Ltd: Oxford, 1992

5 Morris DL. Pre-operative albendazole therapy for hydatid cyst. Br J Surg 1987; 74; 805-806.

6 Çataltepe O, Çolak A, Özcan OE. Intracranial hydatid cysts. Experience with surgical treatment in 120 patients. Neurochirurgica 1992; 35: 108-111.

7 Carey ME. Infections of the spine and spinal cord. In: Youmans JL (eds): Neurological Surrgery W.B. Saunders, Philadelphia: pp 37593781.1990.

8 Pamir MN, Akalan N, Özgen T, Erbengi A. Spinal Hydatid cysts. Surg Neurol 1984; 21: 53-57. 
9 Tekkök IH, Benli K. Primary spinal extradural hydatid disease. Report of a case with magnetic resonance characteristics and pathological correlation. Neurosurgery 1993; 33: 320-323.

10 Braithwaite PA, Lees RF. Vertebral hydatid disease. Radiological assessment. Radiology 1981; 140: $763-766$.

11 Jena A, Tripahti RP, Jain AK. Primary spinal echinococcosis causing paraplegia. Case report with MR and pathological correlation. AJNR 1991; 12: 560 .

12 Marani SAD et al. Hydatid disease: MR imaging study. Radiology 1990; 175: 701-706.

13 L'Espinasse VL. In: Davis (ed) Neurological surgery Lea and Febinge: Philadelphia, 1943, pp 442
14 Bauer BL, Hellwig D. Current endoneurosurgery. In Bauer BL, Brock M, Klinger M (eds): Advances in Neurosurgery SpringerVerlag, Berlin, Heidelberg: pp 113-120, 1994.

15 Mayer HM, Brock M. Percutaneous lumbar discectomy, the Berlin technique In Mayer HM, Brock M, (eds) Springer, Berlin, Heidelberg: New York, 1989, pp $107-117$.

16 Martz RD, Hoff JT. Parasitic and fungal diseases of the central nervous system. In: Youmans JL (eds) Neurological Surgery. W.B. Saunders: Philadelphia, 1990, pp 3742-3758. 